\title{
Application of Optical Techniques in the Characterization of Thermal Stability and Environmental Degradation in High Temperature Superconductors
}

\author{
L. A. Angurel ${ }^{1}$, N. Andrés 2 , M. P. Arroyo ${ }^{2}$, S. Recuero ${ }^{2}$, \\ E. Martínez ${ }^{1}$, J. Pelegrín ${ }^{1}$, F. Lera ${ }^{1}$ and J.M. Andrés ${ }^{3}$ \\ ${ }^{1}$ Instituto de Ciencia de Materiales de Aragón, CSIC-University of Zaragoza \\ ${ }^{2}$ Instituto de Investigación en Ingeniería de Aragón, I3A, University of Zaragoza \\ ${ }^{3}$ Instituto de Carboquímica, CSIC \\ Zaragoza, \\ Spain
}

\section{Introduction}

The possibility of applying non-destructive techniques is important in the characterization of different problems that are associated with the use of high temperature superconducting materials in diverse technological applications. In this context, optical characterization techniques are being implemented in the analysis of several properties of solid materials due to their non-destructive nature. In particular, in some optical techniques the sample is illuminated with a coherent light and the recorded images present a granularity. This granularity is called speckle and its origin comes from the interference of the light scattered by the different points of the surface (Goodman, 1975b; Andrés et al., 2008). In consequence, any change taking place in the surface is immediately transferred to the speckle. Some speckle techniques that use digital recording have been developed. In this work, we present the applicability of Digital Speckle Pattern Interferometry (DSPI) and Digital Speckle Photography (DSP) in the study of two important problems associated with high temperature superconducting materials: the thermal stability and the environmental degradation (Recuero et al., 2005a; Angurel et al., 2006).

Thermal stability is a great challenge in the development of applications. In comparison with low- $T_{c}$ superconductors, thermal properties of High Temperature Superconductors combine higher specific heat values and lower thermal conductivity ones. With these properties, the normal zone propagation velocities in these materials are several orders of magnitude lower than in the classical superconductors (Wang et al., 2007). Due to these properties, usually a hot spot appears in these materials and an important heat amount is generated leading to local temperature increases. Several stabilizing strategies have been used in order to facilitate heat dissipation in higher volumes and to reduce the possibility of local thermal degradation of the material. In addition, a great amount of work is being performed in order to obtain information about quench generation and propagation in High 
Temperature Superconductors. Usually, a local transition to the normal state is induced in the sample while the temporal evolution of the temperature or/ and the electric field along the sample is recorded. Other experimental techniques that have been proposed are acoustic noise detection (Lee et al., 2004), dynamic magneto-optical imaging (Song et al., 2009) or fluorescent paints, which provide a two-dimensional temperature distribution during quench propagation (Ishiyama et al., 2007).

Digital Speckle Pattern Interferometry (DSPI) has also been proposed as an adequate technique to obtain valuable information about quench generation in different high temperature superconductors (Recuero et al., 2005b, Lera et al., 2005, Angurel et al., 2008). DSPI allows us to measure small displacements in diffusively reflecting objects (Rastogi, 2001). In this technique, a fringe pattern is obtained after having compared two specklegrams, one recorded in a reference state and the second one after having produced a deformation in the object. This fringe pattern has the information associated with the displacement of each surface point. DSPI is adequate due to several of its properties: noncontact nature, digital recording, high sensitivity and the possibility of obtaining information of large surfaces. In the case of superconducting materials, the surface deformation is associated with thermal expansion that is originated when a transition to the normal state takes place in any point of the sample and its temperature increases. One of the most important features of this technique is the ability for visualizing where a hot spot will appear before it causes severe damage, thus marking the defective area where further microstructural analyses are to be made looking for the associated defects (Lera et al., 2005). The second problem that will be analysed is the environmental degradation of high temperature superconductors in atmospheres with a high humidity (Argyropoulou et al., 2007). These materials have a strong chemical reactivity with water and for this reason environmental degradation plays an important role in the design of new applications in which effective protective methods have to be considered. Speckle Photography is a technique that has been proposed to study the surface degradation that takes place during corrosion (FrickeBegemann et al., 1999). The technique analyses the decorrelation that takes place in the speckle images due to surface degradation. In this work, we show that Digital Speckle Photography (DSP) is an adequate tool to obtain qualitative and quantitative information about the surface degradation of different materials in different conditions, and, in particular, textured $\mathrm{Bi}_{2} \mathrm{Sr}_{2} \mathrm{CaCu}_{2} \mathrm{O}_{8+\delta}$ (Bi-2212) monoliths (Andrés et al., 2008, Recuero et al., 2008).

In this chapter, section 2 summarises the fundamentals of speckle techniques. Section 3 shows several examples of DSPI applied to the analysis of thermal stability on superconductors: Bi-2212 monoliths and 2G HTS wires. Section 4 analyses the environmental degradation of textured bulk Bi-2212 samples using DSP technique.

\section{Fundamentals of speckle optical techniques}

\subsection{Introduction}

Speckle techniques rely on a basic phenomenon that arises when an optically rough surface is illuminated with a laser. Thus, a granular structure appears over it. These randomly distributed spots are called speckles. The intensity of each speckle is the superposition of many scattered waves with random intensities and phases, coming from different points of the object surface. The specific pattern is related to the microstructure. Changes in the shape or structure of the surface can be measured by comparing scattered speckle fields, which are obtained at different states of the object. Two types of deformations are distinguished: Macroscopic 
deformations, which lead to a bulk movement on the speckle pattern, and changes in the microscopic structure of the surface, which induce modifications in the speckle pattern or decorrelation. Depending on the case, different techniques can be used (Vest, 1979).

Speckle Interferometry is a technique that determines displacements or deformations. An initial image of the object is taken as the reference state. The object is imaged on the sensor of a CCD camera where it is superimposed to a reference beam. New images are taken by the camera after a change in the object is produced. The subtraction of both images produces an image with bright and dark fringes which represent iso-lines of equal deformation. The technique is sensitive to out of plane displacements. It has been used in solids to determine the out of plane deformation (Jones \& Wykes, 1989) and, in fluids, to determine velocities (Andrés et al., 1999; Andrés et al., 2001).

Speckle photography is a technique that compares intensities of the speckle fields and determines alterations on the surface through movements or changes of the speckle pattern. No reference wave is used in these images. Thus, phase information is lost but the method is very simple and easy to use. Traditionally, this technique has been applied to measure the in-plane displacements in solids (Archbold \& Ennos, 1972), deformations (Fricke-Begemann, 2003) and roughness (Yamaguchi et al., 2004).

\subsection{The speckle}

The image recorded when a rough surface is illuminated with white light is different from that obtained when a coherent laser beam is used. An example of a metallic surface sanded with emery paper of 400\# is presented in Fig. 1. In the image obtained with white light (Fig. 1.a) the scratched structure produced by sand paper is distinguished. When the same object is illuminated with a laser beam the image presents a granularity called speckle (Fig. 1.b).

The origin of this granularity is the coherent superposition of many scattered waves with random intensities and phases, coming from different points of the object surface. This process takes place when the sample surface is optically rough, that is, if the surface height variations are greater that the optical wavelength (in this case $\lambda \sim 6 \times 10^{-7} \mathrm{~m}$ ). Thus, a coherent addition of the scattered waves from different object points is obtained. The intensity of each speckle changes from 0 to a maximum value depending on the interference state.

(a)

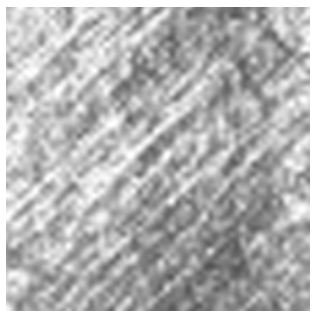

(b)

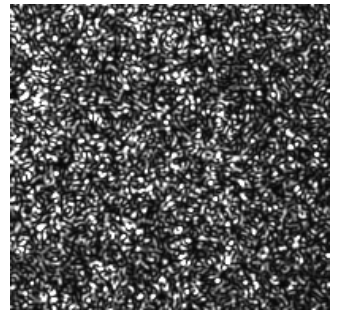

Fig. 1. Recorded images of a metallic sample sanded with emery paper of $400 \#$ and illuminated: (a) with white light and (b) with a coherent laser beam.

A statistical analysis (Goodman, 1975b) is done by assuming that the phases of the small contributions are uniformly distributed over a complete $2 \pi$-interval, that the amplitude and phases are statistically independent variables, and that the number of contributions is sufficiently large. This analysis leads to probability density functions of the intensity I and of the phase of a fully developed, polarized speckle field as follows: 


$$
p(I)=\frac{1}{I} e^{-\frac{I}{\langle I\rangle}} \quad p(\theta)=\frac{1}{2 \pi}
$$

where $\mathrm{p}(\mathrm{I}) \mathrm{dI}$ is the probability for a speckle to have an intensity value between I and I+dI and $p(\theta) d \theta$ is the probability for the phase to have a value between $\theta$ and $\theta+d \theta$.

There are two main geometries to observe the speckles. A freely propagating field, called objective speckle, and the imaged speckle, called subjective speckle, when the object is recorded by means of a lens system. In the techniques described in this section, speckles are recorded on the image plane (subjective speckle). Thus, the speckle mean size $d_{s}$ is determined by the following equation:

$$
d_{s}=1.22 \frac{(1+M) \lambda f}{D}
$$

where $\mathrm{f}$ is the focal length, $\mathrm{M}$ the magnification, $\lambda$ the wavelength and $\mathrm{D}$ the aperture diameter of the recording system.

\subsection{Digital speckle photography (DSP)}

In digital speckle photography, the object is illuminated with a laser beam under an angle $\theta$ and the scattered light is imaged onto a CCD sensor (Fig. 2.a). The lens of the recording system is determined by the required magnification. The speckle size must be bigger than the pixel dimensions. The purpose of this technique is the comparison of two different speckle patterns, corresponding to two object states. The first one is considered as the reference state, and is recorded before the object modification process starts, while the second one is recorded after the surface has been modified.

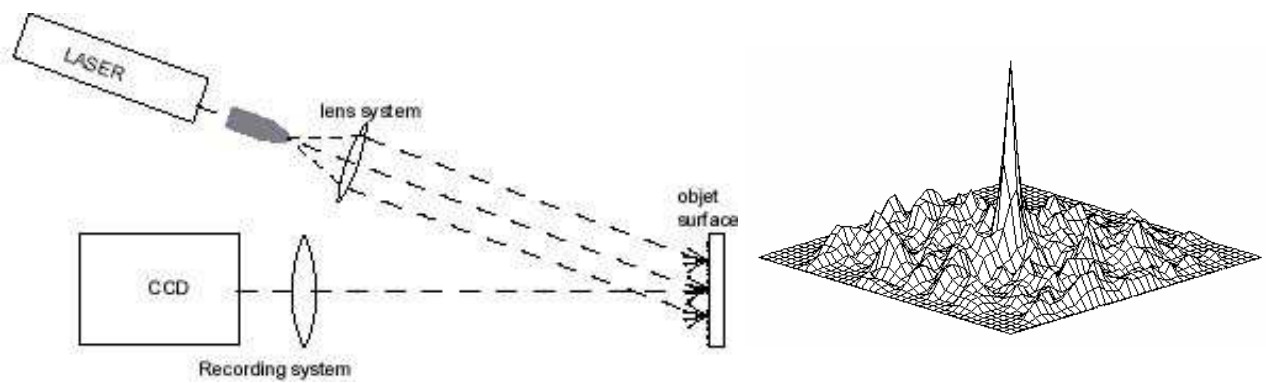

Fig. 2. (a) Digital Speckle Photography recording setup. (b) Plot of a 2D cross correlation function.

As it is a digital recording, each speckle image is a matrix of intensity values, $\mathrm{I}(\mathrm{r})$, associated with the intensity of the interference at each point of the image. The characteristics of the CCD camera determine the intensity level range and the matrix dimensions. Due to the random nature of the speckle fields, changes in the object surface cannot be inferred from each individual speckle. The information has to be extracted through an averaging process. Correlation functions are used to quantify the variation between the intensity fields in two speckle images. The normalized $2 \mathrm{D}$ cross correlation function has been used. It is defined as: 


$$
C C_{I_{1} I_{2}}(\Delta \vec{r})=\frac{\left\langle I_{1}(\vec{r}) I_{2}(\vec{r}+\Delta \vec{r})\right\rangle-\left\langle I_{1}(\vec{r}) I_{2}(\vec{r})\right\rangle}{\left[\left(\left\langle I_{1}^{2}(\vec{r})\right\rangle-\left\langle I_{1}(\vec{r})\right\rangle^{2}\right)\left(\left\langle I_{2}^{2}(\vec{r})\right\rangle-\left\langle I_{2}(\vec{r})\right\rangle^{2}\right)\right]^{1 / 2}}
$$

where $I_{1}(\mathbf{r})$ and $I_{2}(\mathbf{r})$ are the intensity field of the first and second speckle images, respectively. This function has a different value for each $\Delta \mathbf{r}=(\Delta \mathrm{x}, \Delta \mathrm{y})$ (Fig. 2.b), and has a maximum at a certain value. The peak position is proportional to the in-plane sample displacement and its height is related to the surface modifications. Both contributions can be analysed separately. The peak value, also known as the correlation coefficient, changes from 1 , when the surface remains unchanged, to cero that corresponds to a total decorrelation.

The calculation of the $2 \mathrm{D}$ cross correlation function using eq. 3 is a time consuming process, it is numerically implemented with Fast Fourier Transform algorithms (Takeda, 1982). Then:

$$
\left\langle I_{1}(\vec{r}) I_{2}(\vec{r}+\Delta \vec{r})\right\rangle=\left[\mathfrak{J}^{-1}\left[\mathfrak{I}\left[I_{1}\right] \mathfrak{I}\left[I_{2}\right]\right]\right]
$$

where $\mathfrak{I}$ means Fourier Transform. The correlation coefficient can be calculated over the full image or using correlation windows of $\mathrm{N}_{\mathrm{x}} \times \mathrm{N}_{\mathrm{y}}$ pixels. In the first case, the evolution of the correlation coefficient gives a global value of surface changes. As the value at each interrogation area indicates the local changes, the second procedure allows obtaining a $2 \mathrm{D}$ correlation map, with information on where the surface modification process has taken place. The size of the sub-regions has to be big enough for the statistical analysis to be feasible but as small as the size of the defects to be identified.

\subsection{Digital speckle pattern interferometry (DSPI)}

In digital speckle pattern interferometry, the light scattered by the object is made to interfere with a reference beam (Fig. 3). This interference, called specklegram, is recorded on a CCD camera at different time states. The reference wave is obtained by diverting a small amount of the main laser beam. Due to the small spatial resolution of CCD cameras, the angle between both beams has to be very small. Then, both beams are combined in front of the CCD camera by means of a cube beam-splitter (Fig. 3). The sustration of two specklegrams, recorded for different object states, produces an image, whose intensity in each point is proportional to:

$$
\mathrm{I}(\mathrm{x}, \mathrm{y}) \sim(1-\cos \Delta \phi)
$$

where $\Delta \phi$ is the phase difference in the object wave, which is related to the object local displacement as:

$$
\Delta \phi=\mathbf{K} \cdot \mathbf{L}
$$

with $\mathbf{K}=\left(\mathbf{k}_{\mathbf{0}}-\mathbf{k}_{\mathbf{i}}\right)$ the sensitivity vector, being $\mathbf{k}_{\mathbf{i}}$ and $\mathbf{k}_{\mathbf{o}}$ the wave vectors of the illumination and observation beams and $\mathbf{L}$ the surface displacement vector.

Since the fringes are loci of constant phase difference, the deformation vector components can be measured using appropriate configurations. In many cases, the visual aspect of the fringes, that represent regions of equal displacement, can provide enough information in the analysis of a given experiment.

In order to know the quantitative phase difference value, spatial phase shifting (SPS) can be introduced (Burke et al., 1998; Creath, 1985). It is based on the addition of a known phase 
function called phase carrier. A conventional DSPI setup can be turned into a SPS-DSPI setup by shifting the origin of the smooth divergent reference wave with respect to the lens centre an amount $\Delta x$ (Fig. 4). This generates a linear phase shift in the $\mathrm{x}$-direction of the sensor. The phase-shifted data are recorded simultaneously on adjacent pixels, in the same speckle. To resolve this modulation frequency, a phase shift of $2 \pi$ (maximum-minimummaximum) must be recorded in each speckle instead of the constant phase in a standard speckle of a DSPI specklegram. Thus, the speckle size is appropriately increased up to a value of around 3 pixels.

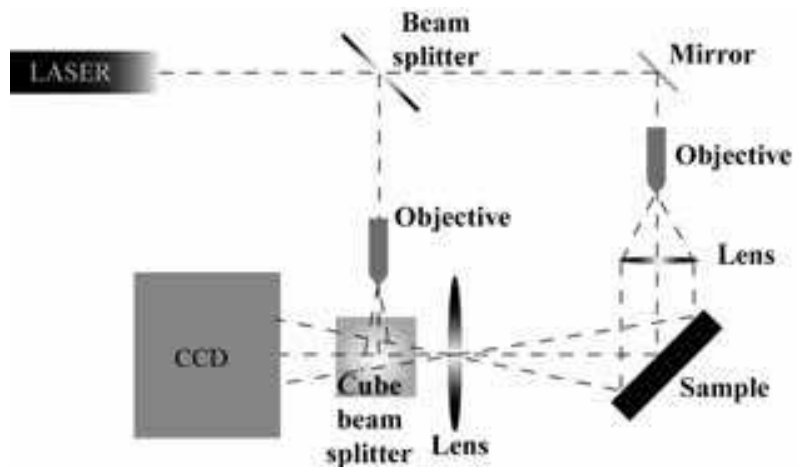

Fig. 3. Digital Speckle Inteferometry setup

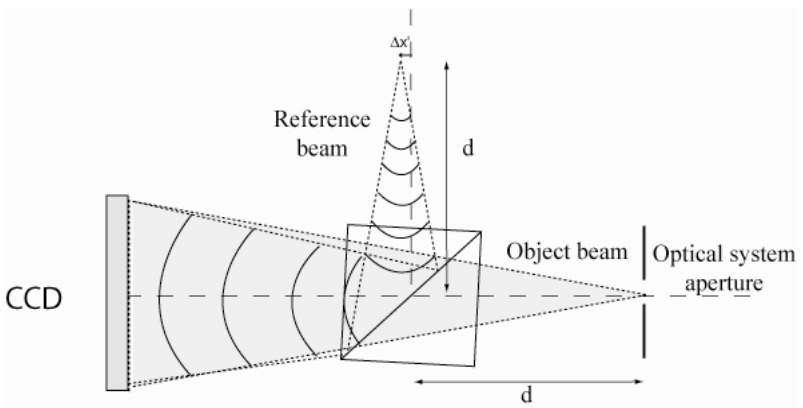

Fig. 4. Experimental setup used for introducing SPS in a DSPI system.

Phase maps are obtained using a global Fourier Transform method (FTM) (Takeda et al., 1982; Lobera et al., 2004). This analysis is based on the calculation of the Fourier transform of the specklegram. The positive frequency side lobe is isolated and translated to the origin to eliminate the carrier frequency component. The inverse discrete Fourier transform is then carried out, and the object phase at each pixel is obtained. A phase difference map, instead of a intensity map, is retrieved by subtracting two object phase maps. For visualization, the phase differences are mapped to grey levels such as that 0 is black and $2 \pi$ is white, given that the phase differences are wrapped (only known in the range 0 to $2 \pi$ ).

Although this technique is more sensitive to out-of-plane displacements, if big changes take place on the surface the correlation between images decreases and then the visibility of the fringe pattern decreases and even disappears. 


\section{Analysis of quench generation in high temperature superconductors using digital speckle pattern interferometry}

In this section we show several examples on the use of DSPI for the analysis of the thermal stability in High Temperature Superconductors. First, we present the experimental modifications needed to apply this technique in cryogenic conditions, as required for the study of superconducting materials, and then we show several examples of inhomogeneity along the length in the transition from superconductor to normal state in different materials.

\subsection{Experimental modifications required to apply DSPI in cryogenic conditions}

In this application, DSPI has to be used while the superconducting material is in the superconducting state, at temperatures close to $77 \mathrm{~K}$. For this reason, it has been necessary to build a new experimental set-up (Recuero et al., 2005). A glass dewar (height of $420 \mathrm{~mm}$ and diameter of $200 \mathrm{~mm}$ ) was designed with several $85 \mathrm{~mm} \times 100 \mathrm{~mm}$ windows with optical access for different optical techniques (Fig. 5.a). This window was heated with an external manganin resistance to avoid any condensation on the external wall that could strongly disturb the DSPI observations.

Two different DSPI configurations have been used in different works. In the first one the sample was illuminated at an angle of $\varphi=45^{\circ}$ (Recuero et al., 2005, Lera et al., 2005). The angle between the illumination and the recording direction was $90^{\circ}$. With this set-up two optical windows were required to illuminate and to observe the sample. The sensitivity of the technique was $0.45 \mu \mathrm{m}$ per fringe. As can be observed in Fig. 5.b, $\varphi$ can be reduced. In the case of the second configuration $\varphi=10^{\circ}$ (Angurel et al., 2008, Angurel et al., 2009), only one optical window was required and the sensitivity increased up to $0.28 \mu \mathrm{m} /$ fringe. In both cases, the size of this window can be adjusted to the sample size.

One of the difficulties to overcome is the need of a stable atmosphere around the sample. In the initial experiments, the sample was fixed to an aluminium plate held at the centre from the dewar top cover and it was cooled by a conduction system, thermally anchored to the aluminium plate, which is partially immersed in liquid nitrogen. In these conditions, the sample cannot be placed inside liquid nitrogen because liquid movements induce some changes in the refraction index that create a random fringe pattern and hide any observation related to the sample deformation. For this reason, the sample was usually placed above the liquid surface and the pressure inside the dewar was reduced to approximately $0.1 \mathrm{~atm}$.

Obviously it is also interesting to obtain information about quench generation with samples immersed in liquid nitrogen because in some applications these superconducting materials have to work in these conditions. A new experimental configuration, with the sample placed very close to the dewar window, was designed (Angurel et al., 2009) (Fig. 5.b). In this case, the sample was placed closer to the dewar wall in order to reduce the light path inside the liquid nitrogen from $20 \mathrm{~cm}$ to $1 \mathrm{~cm}$. The measurement procedure consists on reducing the pressure inside the dewar and wait for approximately 15 minutes. It has been observed that during this time, the random fringe pattern transforms in a series of near horizontal fringes whose number decreases with time (Fig. 6) and finally almost disappears. This means that liquid nitrogen movement changes from a random state to a still stratified one and finally it stabilizes. In these conditions, there is a time window of approximately 10-15 minutes where the sample displacements can be visualized. The sample temperature can be controlled by changing the gas pressure inside the dewar. 

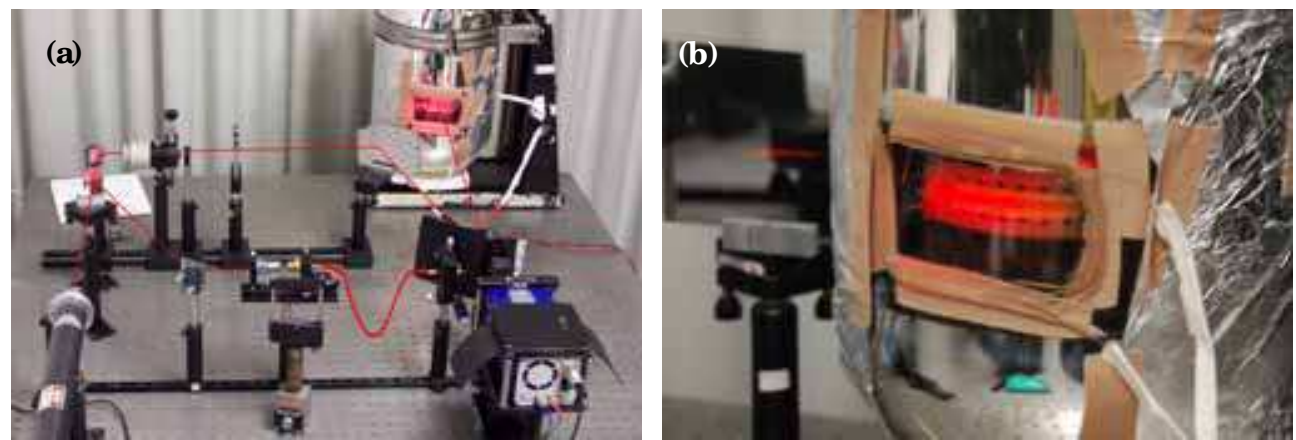

Fig. 5. (a) Experimental arrangement used to apply DSPI in cryogenic conditions. (b) Detail of the modification performed for placing the sample close to the dewar window in order to take measurements with the sample immersed in liquid nitrogen.
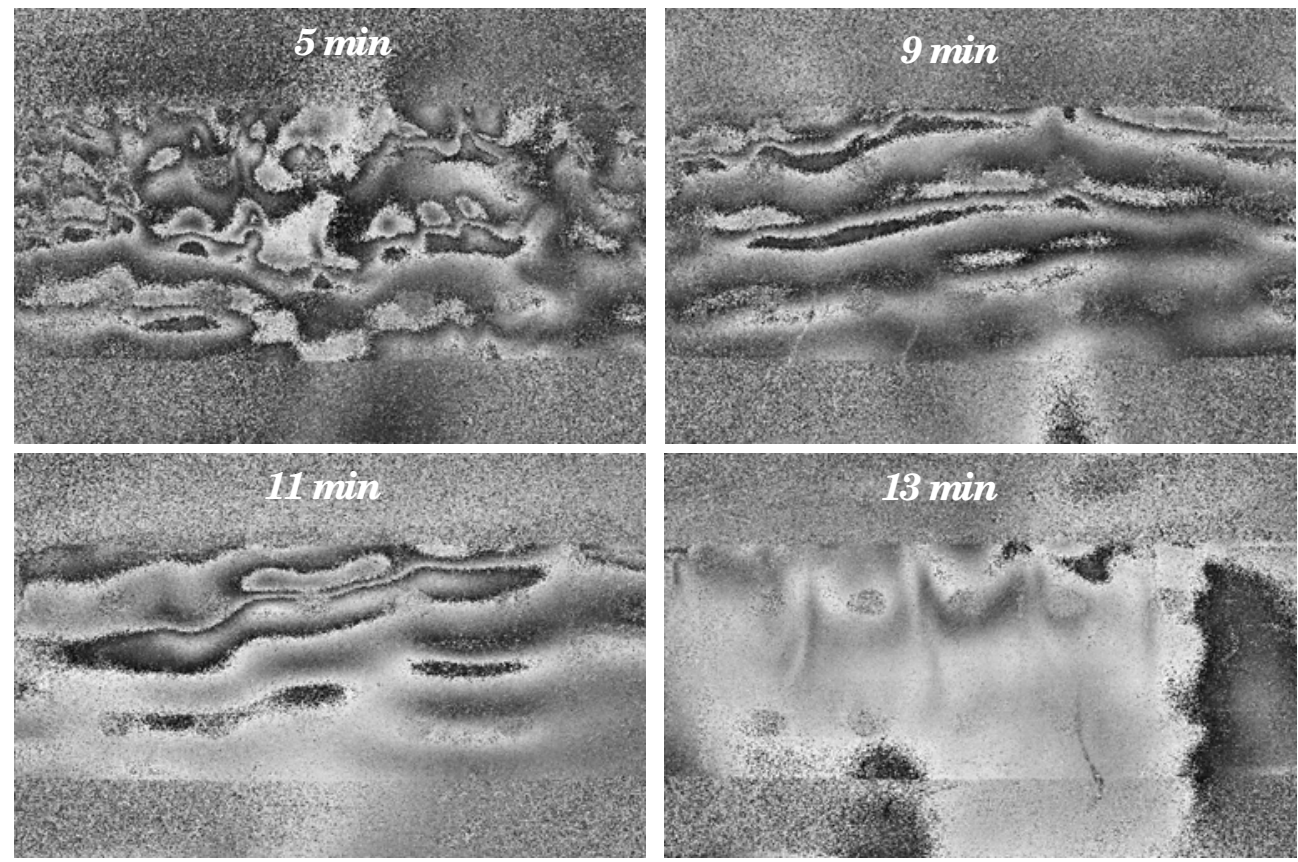

Fig. 6. Fringe patterns associated with liquid nitrogen movements at different instants after having reduced the pressure inside the dewar.

\subsection{Hot spot generation in Bi-2212 monoliths}

Properties of bulk Bi-2212 monoliths are determined by the quality of the intergranular junctions. Laser melting techniques were introduced as an adequate tool to texture these materials in a planar geometry and to obtain good superconducting properties (Mora et al., 2003). When the material transits to the normal state, heat dissipation starts in the points where the junctions have the poorest properties. These materials have very low thermal 
conductivity values and this local heat generation induces inhomogeneous temperature increments that can deteriorate the superconductor.

Experiments were performed with the optical configuration that had a sensitivity of 0.45 $\mu \mathrm{m} /$ fringe for deformations in the direction perpendicular to the sample surface (Recuero et al., 2005; Lera et al., 2005). The sample was fixed by one point to the aluminium plate in order to avoid the movement of the sample and to have a fixed reference point (Fig. 7). The sample and the metallic support were electrically isolated.

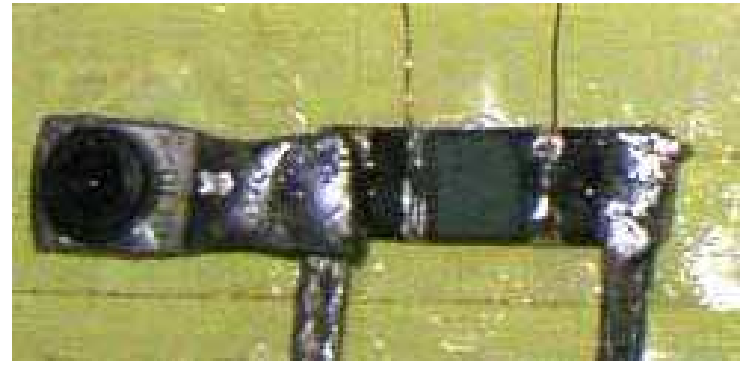

Fig. 7. Photograph of the system used to hold the Bi-2212 monoliths.

An initial characterization was performed at room temperature. In this case, small currents were applied for some seconds and the fringe pattern was recorded. At the same time, the resistance change, which is proportional to the temperature variation, was measured. Fig. 8 shows the time dependence of the resistance that was measured in a Bi-2212 monolith at room temperature for different applied current values. The observed behaviour correlates with the DSPI fringe patterns recorded at different instants (Fig. 9). The fringe pattern corresponds to a bending sample movement with fringes appearing in the image right side. In the case of $1.5 \mathrm{~A}$ only two fringes are observed, they appear at $\mathrm{t}=20 \mathrm{~s}$ and they remain constant during the rest of the pulse. In the case of a current of $2.5 \mathrm{~A}$, the number of fringes increases up to 6 , at $\mathrm{t}=40 \mathrm{~s}$, remaining unchanged afterwards. As in other samples (Lera et al., 2005) the number of fringes is proportional to the resistance change and, in consequence, to the temperature variations. This confirms that the number of fringes is related to the sample deformation associated with thermal expansion.

These monoliths were also characterized at temperatures below $T_{\mathrm{c}}$, applying current pulses higher than the critical current value (Recuero et al., 2005). Samples were cooled by conduction. A rotary pump vacuum was made in order to eliminate unwanted fringe patterns associated with gas movement. As it has been mentioned, in these materials, when a current higher than the critical current value is applied, dissipation starts at the points with the poorer superconducting properties. This is reflected on a different fringe pattern shape. Fringes arise from a point whose location coincides with the point that has the poorer properties. An example in which the applied current is approximately 3 times higher than the critical current is presented in Fig. 10. This was confirmed by applying higher currents values, with the objective of generating enough heat to melt the sample. Results showed that melting was originated in a point (Fig. 10), that coincided with the point where the fringes were originated.

In consequence, DSPI allows determining where a hot spot will be located. The main advantage is that it can be located when the temperature reached by the sample is lower that $100 \mathrm{~K}$. These experimental conditions do not deteriorate the sample. For this reason, these 
studies can be performed combined with microstructural analysis in order to obtain information on the defects that are responsible of the hot spot generation (Lera et al., 2005). In these materials, texture processing induces a microstructure where the grains are very well aligned to the sample axis. DSPI showed that the hot spots were located in regions where many holes, originated during the texturing process, were concentrated.

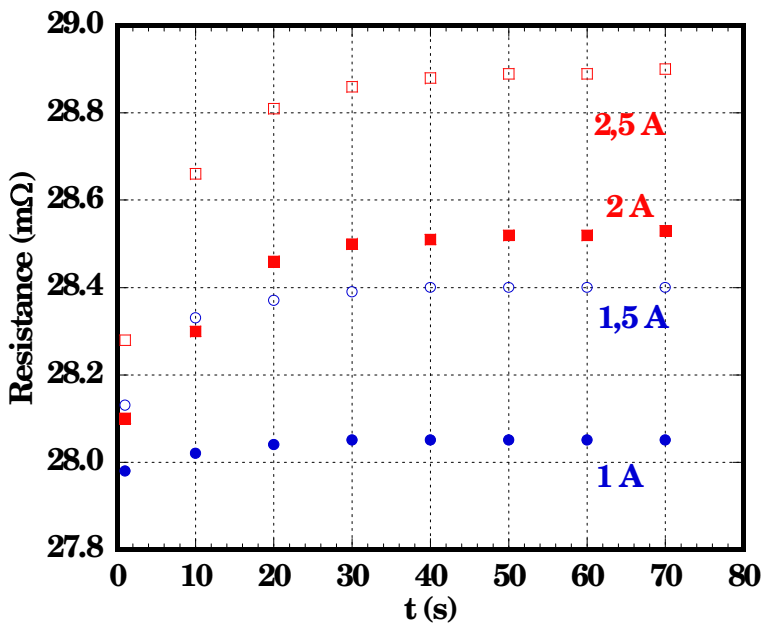

Fig. 8. Time dependence of the Bi-2212 monolith resistance at room temperature for different applied currents.

\section{$1.5 \mathrm{~A}$}

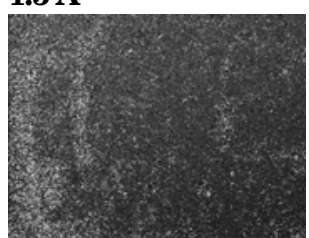

$10 \mathrm{~s}$

\section{$2.5 \mathrm{~A}$}

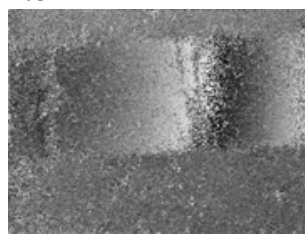

$10 \mathrm{~s}$

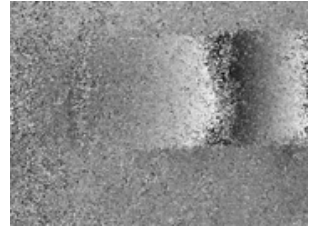

$20 \mathrm{~s}$

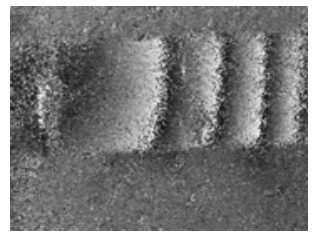

$20 \mathrm{~s}$

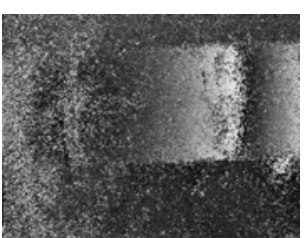

$40 \mathrm{~s}$

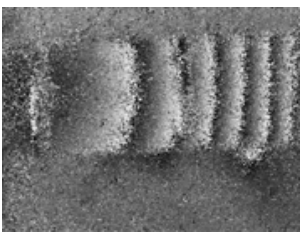

$40 \mathrm{~s}$

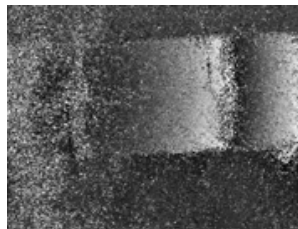

$80 \mathrm{~s}$

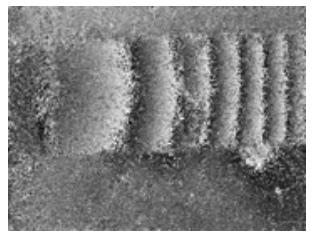

$80 \mathrm{~s}$

Fig. 9. Fringe patterns obtained in a Bi-2212 monolith at room temperature for two applied currents at different times.

This example shows that DSPI observations can be used to obtain information on the origin of hot spots and how the processing conditions can be modified in order to control these defects and to reduce their influence on the final properties of the superconducting material. 

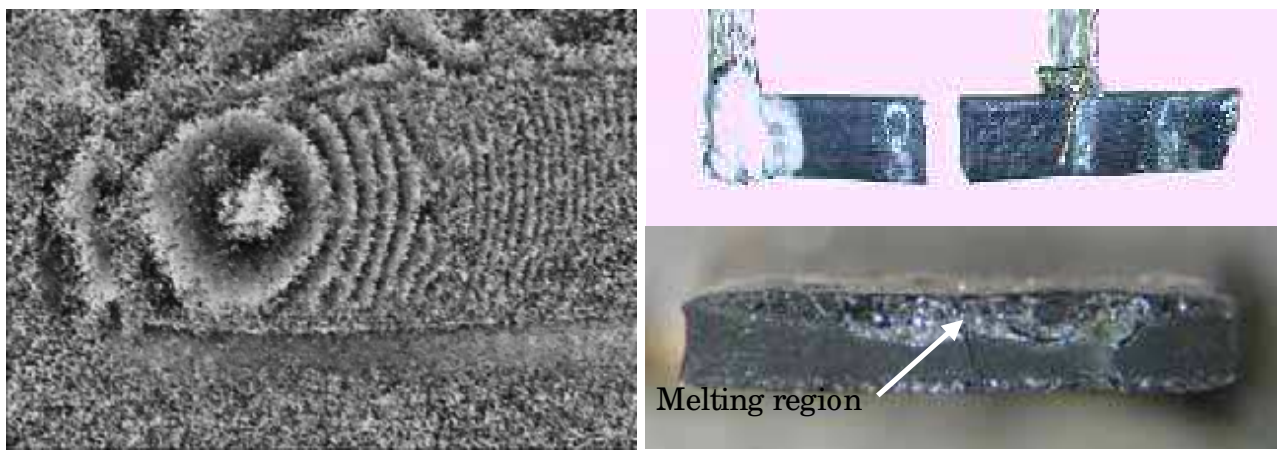

Fig. 10. Fringe pattern observed in a Bi-2212 monolith at low temperature when a current higher that the critical current is applied. Longitudinal and transverse photographs of the sample after having applied a high current pulse that melted it.

\subsection{Quench generation in 2G HTS wires}

Visualization of quench generation in 2G HTS wires has also been analysed using DSPI techniques (Angurel et al., 2008; Angurel et al., 2009). This work is being performed in the framework of a collaboration with SuperPower Inc.. The experiments were done in homogeneous samples as well as in samples with a controlled defect. This defect produced a local reduction of the critical current value at $77 \mathrm{~K}$ to values around a $20 \%$ of the average value. Experiments were performed with the sample placed both above and below the liquid nitrogen level. In the first case, two different cooling conditions were used: with the sample fixed to an isolation sample holder or fixed to a metallic holder. The main result (Angurel et al., 2008) is that quench generation does not always appears in the point with the lower critical current value and that other facts as the cooling conditions or inhomogeneities in the sample thermal stabilization can play a fundamental role.

The results presented here correspond to the case of the sample immersed in liquid nitrogen, as required in many applications of these conductors. For this reason, as it was mentioned in section 3.1, an effort was made for performing DSPI observations in these challenging experimental conditions (Angurel et al., 2009). In addition, the measuring system has been modified in order to obtain simultaneous measurements of the optical properties and of the electric field and temperature profiles during the current pulse.

Fig. 11 and Fig. 12 show the results of the DSPI technique applied to two different samples of the same batch, corresponding to a SCS4050 2G HTS wire with a width of $4 \mathrm{~mm}$ and a 20 $\mu \mathrm{m}$ thick stabilizing copper layer. A special sample holder was designed for allowing both sides of the sample to be in contact with liquid nitrogen or for placing the sample on a metallic support. The sample is fixed at the two ends and, for this reason, the deformation associated with the thermal stabilization leads to the bending of the sample.

Fig. 11 shows the typical behaviour of a homogeneous sample, as it is seen by the electric field and by the temperature profiles, during a pulse of $120 \mathrm{~A}$ for $3 \mathrm{~s}$ while the sample was immersed in liquid nitrogen and $\mathrm{T}=78.6 \mathrm{~K}\left(\mathrm{I}_{\mathrm{c}}(77 \mathrm{~K})=123 \mathrm{~A}\right)$ because the pressure inside the dewar was above atmospheric pressure. Both sides of the sample are in contact with liquid nitrogen. The electric field values at the pulse end is on the order of $3 \times 10^{-4} \mathrm{~V} / \mathrm{cm}$ (Fig. 11.a) and temperature rises less than $0.8 \mathrm{~K}$ (Fig. 11.b). DSPI fringe patterns are presented in Fig. 11.c to 11.h. In this case, the reference state has been recorded before applying the pulse and 

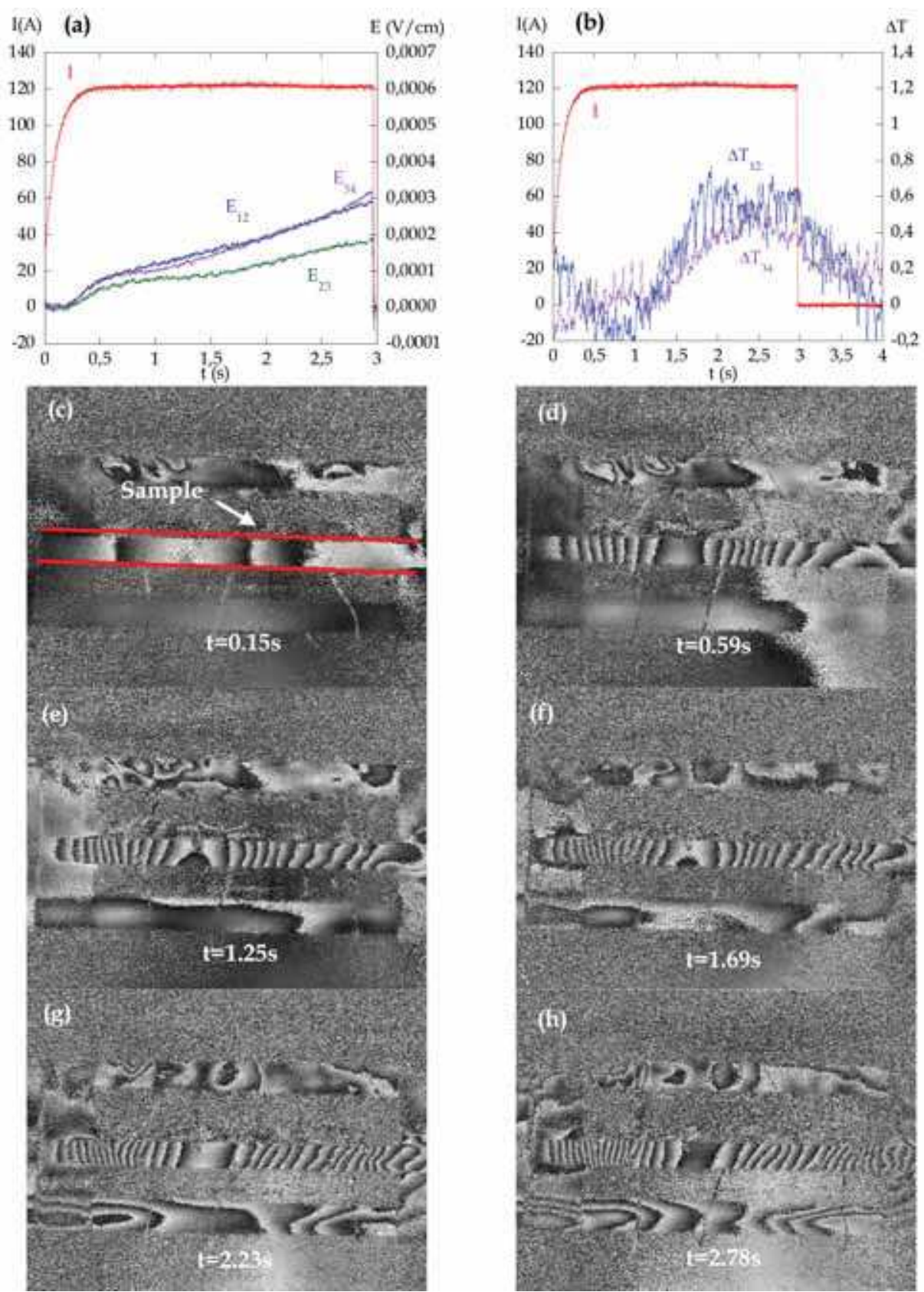

Fig. 11. (a) Electric field and (b) temperature profiles recorded in a 2G HTS wire after applying a current pulse of $120 \mathrm{~A}$ for $3 \mathrm{~s}$ at $78.6 \mathrm{~K}$. (c) to (h) Fringe patterns observed at different instants: $0.15 \mathrm{~s}, 0.59 \mathrm{~s}, 1.25 \mathrm{~s}, 1.69 \mathrm{~s}, 2.23 \mathrm{~s}, 2.78 \mathrm{~s}$, taking as reference $\mathrm{t}=0 \mathrm{~s}$. 

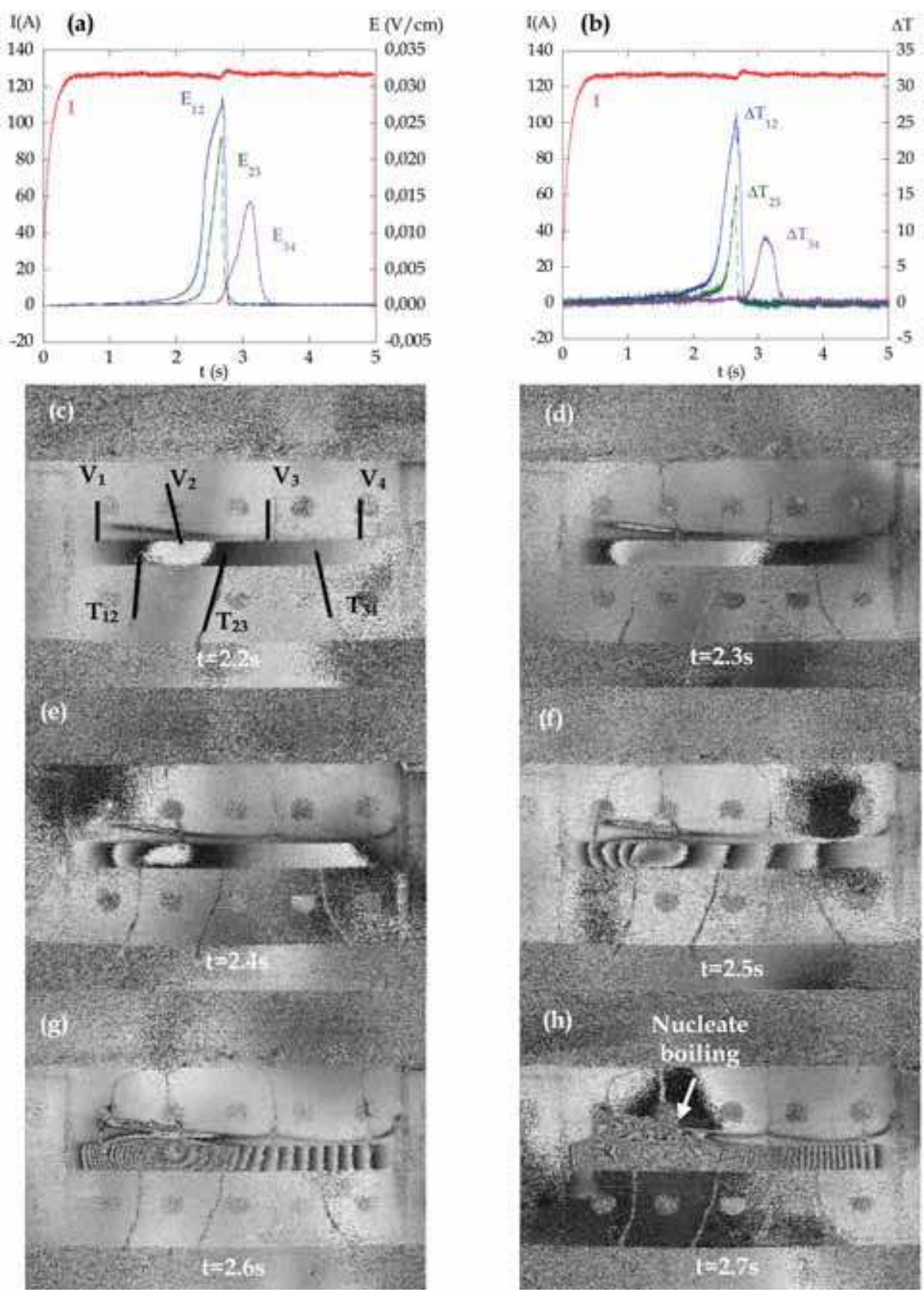

Fig. 12. Behaviour of a sample with a defect in contact $V_{2}$ after having applied a pulse current of $125 \mathrm{~A}$ for $3 \mathrm{~s}$ at $78.6 \mathrm{~K}$. (a) Electric fields and (b) temperature profiles. (c)-(h) Fringes patterns obtained taking as a reference the sample situation at $t=t_{0}-0.1 \mathrm{~s}$. 
for this reason the total deformation is being observed. The fringe patterns at $\mathrm{t}=0.15 \mathrm{~s}$ and $\mathrm{t}=0.59 \mathrm{~s}$ show that in the initial bending deformation stages, the sample takes an S-like shape with a central maximum deformation of $2.2 \mu \mathrm{m}$ (8 fringes) and a minimum one of approximately $0.56 \mu \mathrm{m}$ ( 2 fringes) in the right part of the sample. In the rest of the images, the sample deformation leads to the expected C-liked shape bending deformation of a sample fixed by the two extremes. The number of fringes increases with time in a similar way to the electric field.

DSPI also helps to detect situations in which heat is not generated in a uniform way. This can be seen in Fig 12, which shows the behaviour observed in a 2G HTS wire where a defect was unintentionally produced in the sample when soldering the voltage tap number 2 and a current pulse of $125 \mathrm{~A}$ was applied for $5 \mathrm{~s}$. In this case, the sample was placed on the metallic plate. The electric field generation increases faster in regions 1-2 and 2-3 reaching values of the order of $0.03 \mathrm{~V} / \mathrm{cm}$, two orders of magnitude higher than in the case presented in Fig. 11. At $\mathrm{t}=2.67 \mathrm{~s}$ the electric field in these two regions show a strong reduction that can be also observed in the temperature profiles. They are associated with the increase in the heat transfer coefficient of the liquid nitrogen when moving from the convective to the nucleate boiling regime (Angurel et al., 2008, Martínez et al., 2010). The results indicate that the electric field generation and the temperature increase in region 3-4 start later than in regions 1-2 and 2-3.

In this case, the deformation is much higher than in the previous case, the number of fringes is too high and the resolution is not enough. For this reason, deformation evolution (Fig. 12. $\mathrm{c}-\mathrm{h}$ ) has been visualized taking as the reference the previous image. With this configuration, the observed deformation corresponds to the deformation that took place in the sample during the previous $0.1 \mathrm{~s}$. At $\mathrm{t}=2.2 \mathrm{~s}$, deformation and, in consequence, heat generation is located in the position of voltage contact $V_{2}$. In the region between contacts $V_{3}$ and $V_{4}$ the sample does not deform. This is also consistent with the measured temperature profiles evolution. $\Delta \mathrm{T}_{34}$ starts to increase later on. $\mathrm{At} \mathrm{t}=2.4 \mathrm{~s}$ the heat generated in the sample, in the left part, is enough to induce some movement of the liquid nitrogen above the sample. In the last two photographs, the nucleate boiling has started between contacts $V_{1}$ and $V_{3}$ and the fringe pattern can not be observed, while in the right part of the sample, region $3-4$, the different fringes can clearly be observed.

These results indicate that DSPI observations provide information that is complementary to the electric field and temperature profiles. The main advantage is that DSPI provides precise local information and determines with a good resolution where the origin of the heat generation is placed and that this information can be inferred without anchoring any voltage tap or thermocouple on the sample.

\section{Analysis of environmental degradation in textured bulk $\mathrm{Bi}_{2} \mathrm{Sr}_{2} \mathrm{CaCu}_{2} \mathrm{O}_{8+\delta}$ monoliths obtained by laser melting techniques.}

\subsection{Applicability of digital speckle photography on the analysis of local surface modifications in metallic materials.}

Before studying the surface degradation in $\mathrm{Bi}_{2} \mathrm{Sr}_{2} \mathrm{CaCu}_{2} \mathrm{O}_{8+\delta}$ monoliths, the possibilities of the DSP technique have been explored on the analysis of well known corrosion processes of metallic samples in different conditions. First, we analysed the corrosion of Fe samples in $\mathrm{H}_{2} \mathrm{SO}_{4}$ solutions with different concentrations (Andrés et al., 2008). In this case, the corrosion process produces the generation of $\mathrm{H}_{2}$ bubbles in the metallic surface. These bubbles are clearly observed in Fig. 13.a in the case of a Fe sample after having been immersed $40 \mathrm{~s}$ in a $0.1 \mathrm{~N} \mathrm{H}_{2} \mathrm{SO}_{4}$ solution. These bubbles prevent the information about the surface state in these points from being obtained (Fig. 13.b). 

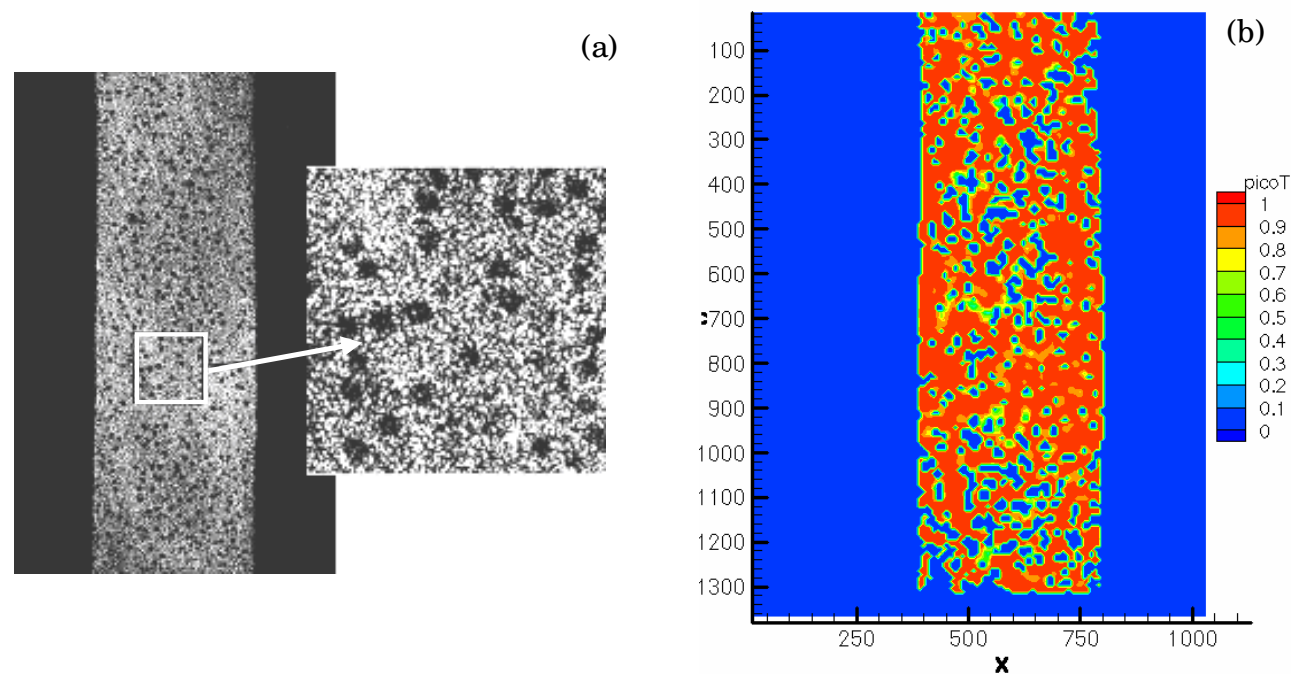

Fig. 13. (a) Image of speckle photography from a Fe sample after being immersed in a $0.1 \mathrm{~N}$ $\mathrm{H}_{2} \mathrm{SO}_{4}$ solution for $40 \mathrm{~s}$. (b) 2-D correlation coefficient map measured in these conditions.

For this reason, when corrosion takes place in an acid solution, these studies were performed by recording the images with the sample removed from the solution. It was observed that the time dependence of the correlation coefficient is linear in the initial $250 \mathrm{~s}$, when the correlation coefficient value reduces down to 0.6 . It was proposed that the slope of this variation is related to the corrosion rate of Fe in these conditions. DSP observations have been compared with linear sweep voltametry measurements. This comparison showed that DSP can be used to compare corrosion rates in different conditions.

A second problem that has been analysed is when the corrosion process involves the deposition of a layer on the surface. This is the case of Fe samples immersed in $\mathrm{Cu}\left(\mathrm{NO}_{3}\right)_{2}$ solutions, where a copper layer is deposited on the Fe surface. Samples have been sanded with emery paper of $400 \#$ which produces a scratched structure on the surface (Fig. 14.a).

The maximum scratch depth is $1.2 \mu \mathrm{m}$. DSP observations (Fig. 14.b) clearly show that the corrosion is not uniform being more important in the central and right part of the sample, where the correlation coefficient has lower values.

In order to find a relation between the correlation coefficient variations and the modifications taking place on the sample surface, the topography along the line indicated in Fig 14.b has been measured using confocal microscopy. Results are compared in Fig. 15, where each image corresponds to a $1.1 \mathrm{~mm}$ length. In Fig. 15.a and 15.b, the left part of the region, with the highest values of the correlation coefficient, is presented. Between pixels 390 and 420, where the correlation coefficient remains close to 1 , the surface was not modified. In the regions where the correlation coefficient is reduced to values between 0.8 and 0.9 the surface becomes smoother. Around pixel 430, the correlation coefficient value is close to 0.7. In this region, $\mathrm{Cu}$ deposition is observed with small aggregates, 1 to $2 \mu \mathrm{m}$ thick. A region with higher variations is observed in Fig. 15.c and 15.d. The correlation coefficient reaches values between 0.2 and 0.3 . In this case, the $\mathrm{Cu}$ layer completely covers the $\mathrm{Fe}$ surface reaching a layer thickness close to $8 \mu \mathrm{m}$. 
These results clearly show that DSP is a technique that can be used to compare the corrosion rate in different experimental conditions. One of the main advantages is that it is possible to obtain local information of how the corrosion process evolves in different regions of the surface.

(a)

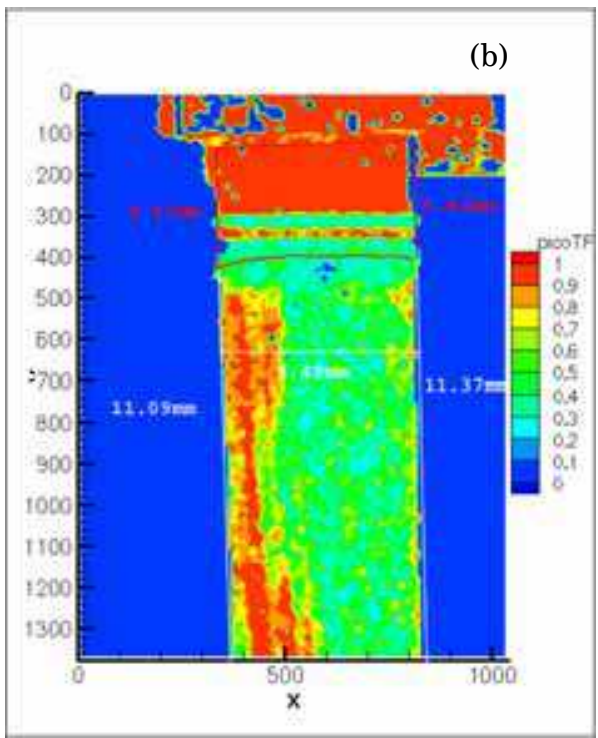

Fig. 14. (a) Confocal image of the Fe surface $\left(255 \times 190 \mu \mathrm{m}^{2}\right)$ before starting the deposition process. (b) $2 \mathrm{D}$ correlation map obtained in a Fe sample after being immersed in a $0.1 \mathrm{M}$ $\mathrm{Cu}\left(\mathrm{NO}_{3}\right)_{2}$ solution for $1 \mathrm{~h}$.

(a)

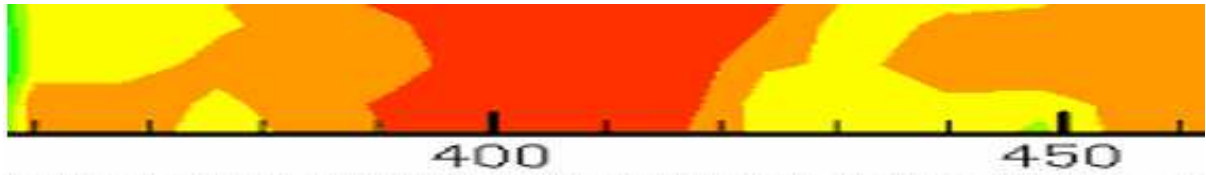

(b)

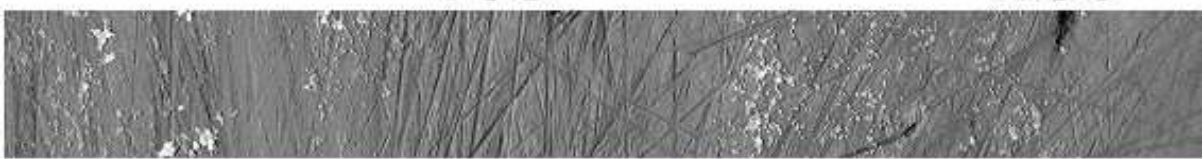

(c)

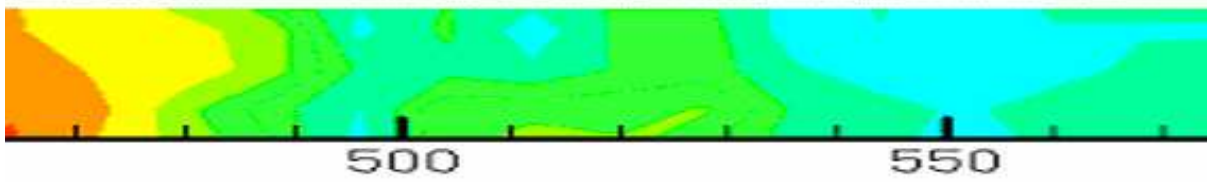

(d)

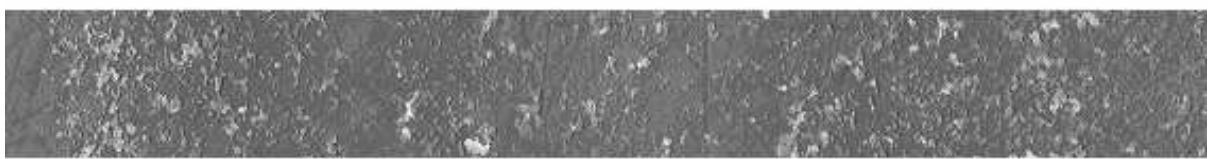

Fig. 15. Comparison of the 2D correlation coefficient map and the surface topography measured with confocal micrscopy in the line shown in Fig. 14.b. 


\subsection{Analysis of the environmental degradation process in textured $\mathrm{Bi}-2212$ monoliths}

The application of melting techniques to fabricate $\mathrm{Bi}-2212$ monoliths produces a multiphase material (Mora et al., 2003). The as-grown material is composed of the $\mathrm{Bi}_{2} \mathrm{Sr}_{2} \mathrm{CuO}_{6}$ (Bi-2201) phase as the main phase and the $(\mathrm{Sr}, \mathrm{Ca}) \mathrm{CuO}_{2}$ oxide as the secondary one. After annealing, the $\mathrm{Bi}-2212$ becomes the predominant phase but some amounts of the $\mathrm{Bi}-2201$ and the $(\mathrm{Sr}, \mathrm{Ca}) \mathrm{CuO}_{2}$ phases remain. These differences in the phase composition can affect the resistance of these materials to environmental degradation.

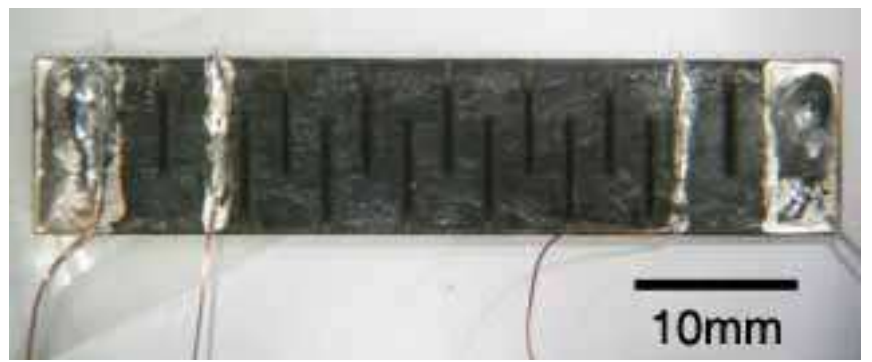

Fig. 16. Bi-2212 coating on a $\mathrm{MgO}$ substrate used for environmental degradation experiments with the sample immersed in water.

Initial tests were performed with the samples immersed in water. Fig. 16 shows an example of a Bi-2212 coating on a $\mathrm{MgO}$ substrate (Mora et al., 2004) where these initial tests were performed. The sample was machined with meander geometry in order to explore the possibility of using these materials in resistive fault current limiters (López-Gascón, 2005). DSP observations are presented in Fig. 17. A magnification of 0.61 was used, and the observation surface is $15 \mathrm{~mm} \times 10 \mathrm{~mm}$, that covers 5 machined lines. Fig. 17.a shows the image of the analysed surface. After $10 \mathrm{~s}$, the 2D correlation map shows that some surface changes have started close to the machined lines (Fig. 17.b). This process evolves as can be observed in Fig. 17.c where the 2D correlation map after $60 \mathrm{~s}$ is presented. It is observed that in the regions close to the machined lines, the correlation values are lower while in the other regions, the surface has not degraded.

Immersing the samples in water is not the best procedure because surface degradation processes are too fast and in these ceramic samples some air bubbles appear on the sample surface. Thus, the next tests were performed placing the superconducting samples inside a small chamber with a relative humidity value of a 93\% (Recuero et al., 2008). These experimental conditions were used to compare the resistance of as-grown and annealed samples to environmental degradation. DSP observations in textured Bi-2212 monoliths were compared with other complementary characterization techniques: diffuse reflectance infrared spectroscopy (DRIFT), X-ray diffractometry (XRD) and scanning electron microscopy (SEM). DSP observations showed that the correlation was lost faster in the asgrown sample indicating a faster surface degradation.

The ( $\mathrm{Sr}, \mathrm{Ca}) \mathrm{CuO}_{2}$ grains that are close to the surface decompose to an amorphous phase that is responsible of the swollen regions that appear in the superconductor surface (Fig. 18). This modification is responsible of the reduction in the correlation coefficient values. The amount of this phase is higher in the as-grown samples. For this reason, the observed reduction in the correlation coefficient value is 3.5 times faster in the as-grown samples than in the annealed ones. In consequence, the environmental degradation in the as-grown 
samples is 3.5 times faster. One of the main advantages of the DSP measurements is that this conclusion can be obtained just $60 \mathrm{~s}$ after having started the experiments.

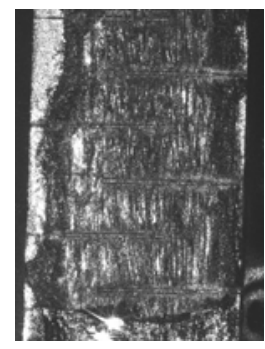

(a)

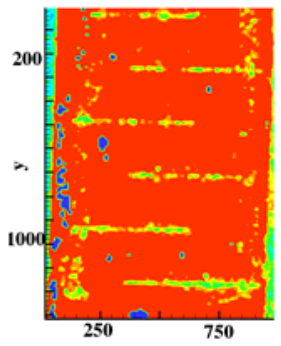

(b)

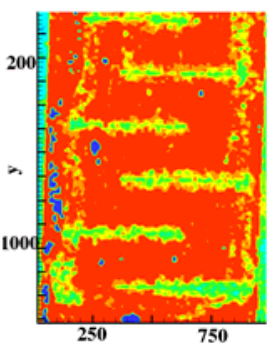

(c)

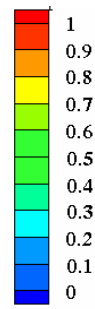

Fig. 17. (a) Image of the analysed surface. (b) $2 \mathrm{D}$ correlation map after $10 \mathrm{s.}$ (c) 2D correlation map after $60 \mathrm{~s}$.

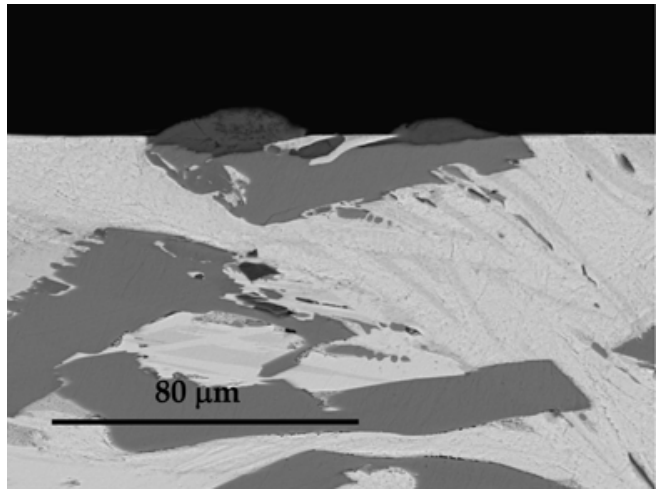

Fig. 18. SEM micrograph showing the decomposition of the $(\mathrm{Sr}, \mathrm{Ca}) \mathrm{CuO}_{2}$ phase due to the reaction with moisture.

The second advantage of the DSP is that these $2 \mathrm{D}$ observations provide information about how the surface degradation evolves in different regions of the sample. In addition, DSP measurements allow determining how the degradation process changes with time. If the reference is taken at an instant $t$, the correlation maps visualize the changes that have taken place from this instant.

\subsection{Influence of laser ablation machining process in the environmental degradation resistance of $\mathrm{Bi}-2212$ monoliths}

One of the problems associated with the ceramic nature of high temperature superconductors are the difficulties associated with machining without introducing mechanical defects in the sample. One of the alternatives is to use laser ablation techniques (López-Gascón, 2005). This technology allows obtaining samples with different geometries or to machine meander geometries in the sample (Angurel et al, 2006).

When this machining process is performed with a nanosecond pulsed laser, an amount of superconductor is melted during the ablation. Fig. 19.a shows that, in the surface of the machined regions there is a layer of melted material with a thickness of approximately $1 \mu \mathrm{m}$. 
In consequence, the $(\mathrm{Sr}, \mathrm{Ca}) \mathrm{CuO}_{2}$ phase does not reach the surface. If the environmental degradation is due to the chemical decomposition of this phase, laser ablation can modify the resistance of these materials to environmental degradation. Another factor related to the microstructure of these materials is that it is not uniform as the $(\mathrm{Sr}, \mathrm{Ca}) \mathrm{CuO}_{2}$ phase is mainly concentrated close to the sample surface. In order to study these effects several $4 \mathrm{~mm} \times 5 \mathrm{~mm}$ rectangles have been machined in $1 \mathrm{~cm}$ wide samples (Fig. 19.b). The depth of these machined regions increases from number 1 to 5: 60, 100, 220, 300 and $480 \mu \mathrm{m}$. Environmental degradation tests for both as-grown and annealed samples have been performed using the humidity chamber procedure.
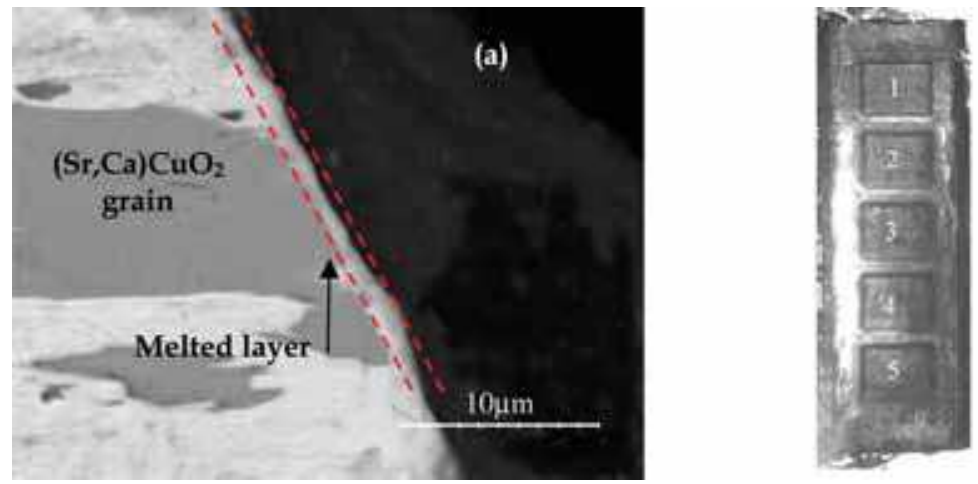

Fig. 19. (a) Detail of the surface of a machined region showing the external layer of melted material. (b) Photograph of a textured Bi-2212 sample showing the machined regions obtained with laser ablation.

Fig 20 shows the 2D correlation maps measured in the as-grown sample. It can be observed that the degradation process is slower in all the machined regions. The degradation rate increases slowly when the machined region depth increases. The behaviour observed in region 5 is similar to the non-machined regions. In consequence, the laser ablation process of as-grown Bi-2212 textured materials reduces the chemical interaction with water of the sample surface, at least in the initial instants.

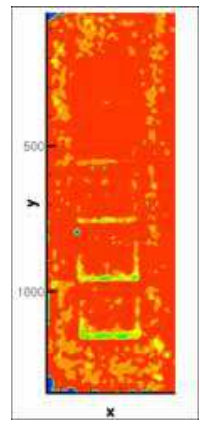

$10 \mathrm{~s}$

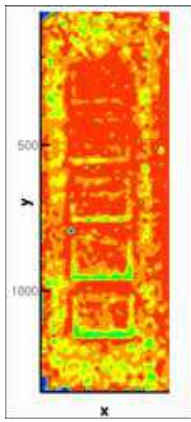

$20 \mathrm{~s}$

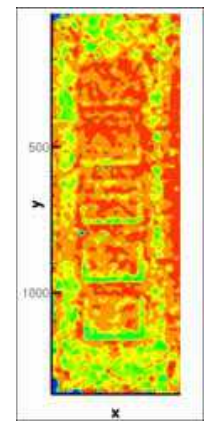

$30 \mathrm{~s}$

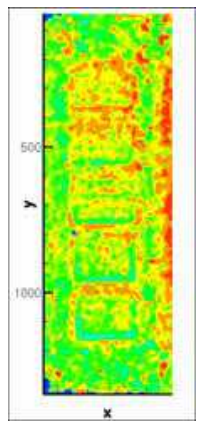

$70 \mathrm{~s}$

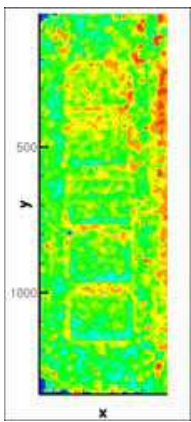

$100 \mathrm{~s}$

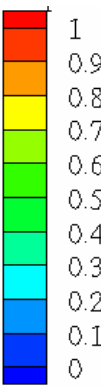

0.9

0.8

0.7

0.6

0.5

0.4

0.3

0.2

. 1 0

Fig. 20. 2D correlation maps of the as-gown sample with different machined regions at different instants. The reference corresponds to the surface state at $\mathrm{t}=0 \mathrm{~s}$. 
This evolution has also been analysed by comparing the time dependence of the correlation coefficient value of a rectangle of $180 \times 140$ pixels in each region (Fig. 21). From the slope of this dependence it is possible to infer that the degradation rate is 2.6 times faster in the nonmachined region than in region 1 . But there is another interesting fact. For longer times degradation in the non-machined region seems to stabilize and it becomes faster in the machined ones. This can be confirmed looking to the time evolution of the correlation coefficient (Fig. 21.b) and the 2D correlation maps (Fig. 22) that have been obtained taking as reference the situation of the sample at $\mathrm{t}=1800 \mathrm{~s}$.
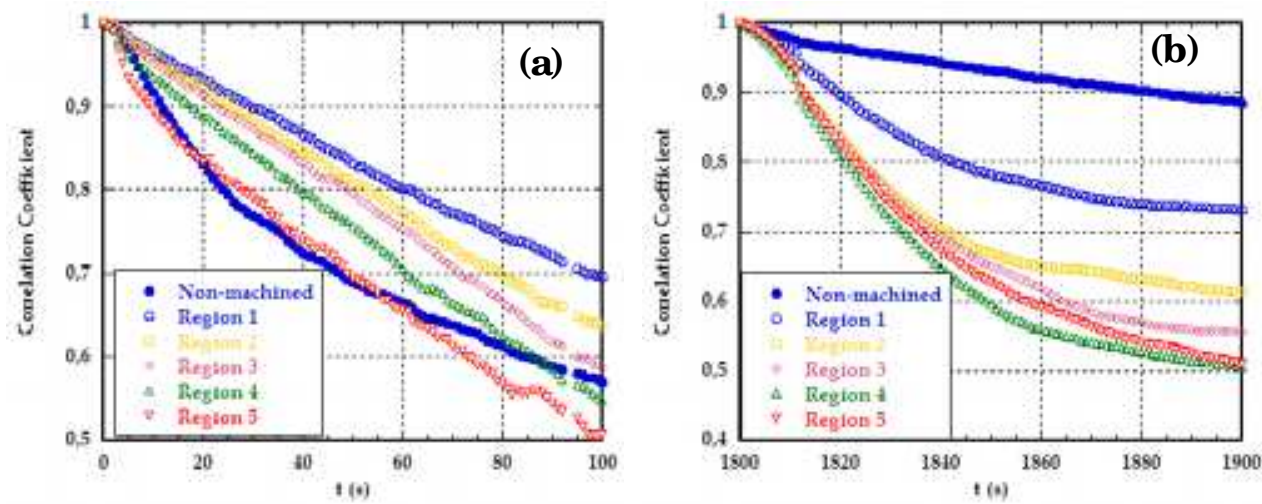

Fig. 21. Time evolution of the correlation coefficient in the different regions of the as-grown samples. The reference has been taken at (a) $t=0 s$ and at (b) $t=1800 s$.

In the case of the annealed samples, the behaviour is slightly different. Degradation rate in the machined regions is faster (Fig. 23) than in the non-machined ones. Another difference is that the behaviour of all the machined regions is much more similar than in the as-grown samples.
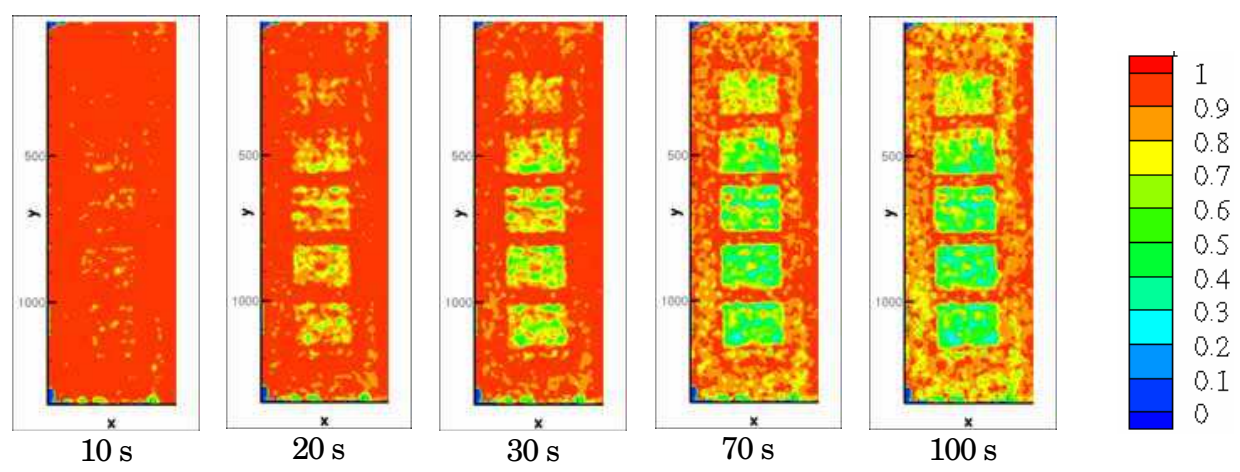

Fig. 22. 2D correlation maps of the as-gown sample with different machined regions at different instants. The reference corresponds to the sample surface at $\mathrm{t}=1800 \mathrm{~s}$. 


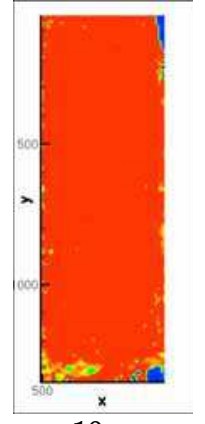

$10 \mathrm{~s}$
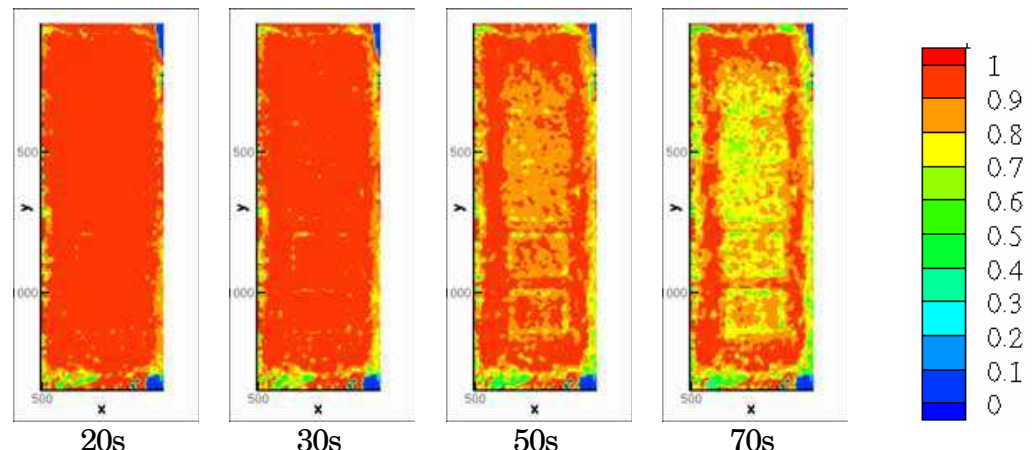

Fig. 23. 2D correlation maps of the annealed sample with different machined regions at different instants. The reference is the sample surface at $t=0 \mathrm{~s}$.

\section{Conclusions and future research}

These results show that optical techniques are valuable tools to obtain information about the behaviour of superconducting materials, relevant to the design of different technological applications. In particular, problems with quench generation and environmental degradation have been studied.

DSPI can be used to visualize different heat generation processes that take place in superconducting materials depending on the cooling conditions. It can be used to detect where a hot spot will take place before damaging the sample. In consequence, it can help to find out which are the microstructural defects that are more important in heat generation and propagation. This has been applied in the analysis of bulk Bi-2212 monoliths and $2 \mathrm{G}$ HTS wires. In the case of bulk materials this information can be used to modify the processing parameters in order to eliminate these defects or to distribute them in the sample in order to homogenise the transition to the normal state. In the case of $2 \mathrm{G}$ HTS wires DSPI measurements visualize if the sample presents a homogeneous or an inhomogeneous transition to the normal state. This information has been confirmed with the direct measurement of the electric field and temperatures profiles. The main advantage is that DSPI does not require soldering voltage taps or thermocouples in the sample.

One of the objectives for the future research is to obtain quench parameters from the optical observations. This is not a simple task because the deformations that are observed also depend on the sample mechanical constraints. For this reason, in order to obtain quantitative information from these measurements, thermo-mechanical models are being developed in order to be able of determining the temperature profile from the mechanical deformation.

DSP has provided useful information about environmental degradation of bulk superconducting materials. The chemical reactions that take place modify the surface characteristics and, in consequence, reduce the correlation coefficient values. The main advantage of this technique in comparison with other experimental techniques is that it provides 2D local information in the very early stages of the degradation process. In addition, if the reference image is changed from the initial state to any other at a given time, 
the evolution of the degradation processes from this instant can be determined. This allows evaluating how the degradation process rate evolves at any instant.

In the case of the Bi-2212 monoliths, it has been established that the surface degradation is associated with $(\mathrm{Sr}, \mathrm{Ca}) \mathrm{CuO}_{2}$ chemical decomposition. DSP has shown that this process is faster in the as-grown samples than in the annealed ones. In addition, this optical technique has also been applied to quantify the change in the degradation rate when the samples are machined with laser ablation techniques.

\section{Acknowledgments}

Authors thank the Spanish Ministry of Science and Innovation (Projects MAT-2008-05983C03-01 to -03) and the Gobierno de Aragón (Research groups T12, T61 and T76) for financial support of this research. Authors are also obliged to SuperPower, Inc and, in particular, to Dr. V. Selvamanickam and Dr. Y.-Y. Xie for their collaboration in applying these techniques in 2G HTS wires. Finally authors also thank Prof. G. de la Fuente and Dr. C. López-Gascón for their collaboration in applying laser ablation techniques in Bi-2212 monoliths.

*Present address: Instituto Tecnológico de Óptica, Color e Imagen (AIDO), Spain

\section{References}

Andrés, N.; Arroyo, M. P.; Hinrichs, H. \& Quintanilla, M. (1999). Digital speckle interferometry as a full-field fluid-velocity technique. Opt. Lett., Vol. 24, No. 9, 575577, ISSN: 0146-9592

Andrés, N.; Arroyo, M. P.; Zahn, H. \& Hinrichs, H. (2001). Application of digital speckle pattern interferometry for fluid velocimetry in wind tunnel flows. Exp. Fluids, Vol. 30, No. 5, 562-567, ISSN: 0732-4864

Andrés, N.; Recuero, S.; Arroyo, M. P.; Bona, M. T.; Andrés, J. M. \& Angurel, L. A. (2008). Fast visualization of corrosion processes using digital speckle photography. Corrosion Science, Vol. 50, No. 10, 2965-2971, ISSN: 0010-938X

Angurel, L. A.; Díez, J. C.; De la Fuente, G. F.; Gimeno, F.; Lera, F.; López-Gascón, C.; Martínez, E.; Mora, M.; Navarro, R.; Sotelo, A.; Andrés, N.; Recuero, S. \& Arroyo, M. P. (2006). Laser technologies applied to the fabrication and characterization of bulk Bi-2212 superconducting materials for power applications. Phys. stat. sol. (a), Vol. 203, No. 11, 2931-2937, ISSN: 0031-8965

Angurel, L. A.; Martínez, E.; Lera, F.; Recuero, S.; Andrés, N.; Arroyo, M. P.; Xie, Y. Y. \& Selvamanickam, V. (2008). Quench detection in $\mathrm{YBa}_{2} \mathrm{Cu}_{3} \mathrm{O}_{7-\delta}$ coated conductors using interferometric techniques. el Appl. Phys., Vol. 104, No. 9, 093916, ISSN: 00218979

Angurel, L. A.; Martínez, E.; Lera, F.; Recuero, S.; Andrés, N.; Arroyo, M. P.; Xie, Y. Y. \& Selvamanickam, V. (2009). Analysis of Quench Initiation in YBCO Coated Conductors Using Optical Interferometric Techniques. IEEE Trans. Appl. Supercond, Vol. 19, No. 3, 3479-3482, ISSN: 1051-8223

Archbold, E. \& Ennos, A. E. (1972). Displacement measurement from double-exposure laser photographs, Opt. Acta, Vol. 19, No. 4, 253-271, ISSN:0030-3909

Argyropoulou, R.; Ochsenkuhn-Petropoulou, M.; Dounis, C.; Karaboulis, P.; Altzumailis, A. \& Ochsenkuhn K. M. (2007). Comparison of the behaviour of the three 
superconductors $\mathrm{YBCO}, \mathrm{Bi}-2212$ and $\mathrm{MgB}_{2}$ in different environmental conditions. $C$ Mat. Proc. Technol., Vol. 181, No. 1-3, 2-5, ISSN: 0924-0136

Burke, J.; Helmers, H.; Kunze, C. \& Wilkens, V. (1998). Speckle intensity and phase gradients: influence on fringe quality in spatial phase shifting ESPI-systems. Opt. Comm., Vol. 152, No. 1-3, 144-152, ISSN: 0030-4018

Creath, K. (1985). Phase-Shifting Speckle Interferometry. App. Opt., Vol. 24, No. 18, 30533058, ISSN: 0003-6935

Fricke-Begemann, T.; Gulker, G.; Hinsch, K. D. \& Wolff, K. (1999). Corrosion monitoring with speckle correlation. App. Opt., Vol. 38, No. 28, 5948-5955, ISSN: 0003-6935

Fricke-Begemann, T. (2003). Three-dimensional deformation field measurement with digital speckle correlation. App. Opt., Vol. 42, No. 34, 6783-6796, ISSN: 003-6935

Goodman, J. W. (1975). Introduction to Fourier optics, Roberts \& Company Publishers, ISBN:007-024254-2

Goodman, J. W (1975). Static properties of laser speckle patterns, in: Laser Speckle and Related Phenomena, J. C. Dainty (Ed.), 9-74, Springer Verlag, ISBN: 0387074988, Berlin

Ishiyama, A.; Tsuchida, M.; Ueda, H. \& Shiohara, Y. (2007). Assessment of cryogenic thermography system using commercial fluorescent paints on their applicability to visualization of normal-zone propagation in YBCO coated conductors, IEEE Trans. Appl. Supercond., Vol. 17, No. 2, 3765-3768, ISSN: 1051-8223

Jones, R. \& Wykes, C. (1989). Holographic and Speckle Interferometry, Cambridge University Press, ISBN: 0-521-34878-1

Lee, H.; Kim, H. M.; Jankow ski, J. \& Iwasa, Y. (2004). Detection of “hot spots” in HTS coils and test samples with acoustic emission signals. IEEE Trans. Appl. Supercond, Vol. 14, No. 2, 1298-1301, ISSN: 1051-8223

Lera, F.; Angurel, L. A.; Rojo, J. A.; Mora, M.; Recuero, S.; Arroyo, M. P. \& Andrés, N. (2005). Microstructure origin of hot spots in textured laser zone melting Bi-2212 monoliths. Supercond. Sci. Technol., Vol. 18, No. 11, 1489-1495, ISSN: 0953-2048

Lobera, J.; Andrés, N. \& Arroyo, M. P. (2004). From ESPI to Digital Image Plane Holography (DIPH): Requirements, possibilities and limitations for velocity measurements in a 3-D region, in: Particle image velocimetry: Recent improvements, Stanislas, M.; Westerweel, J. \& Kompenhans, J. (Ed.), 363-372, Springer-Verlag, ISBN: 3-54021423-2, Berlin

López-Gascón, C. (2005). Procesado y mecanizado de cerámicas superconductoras de Bi-2212 con técnicas láser. $\mathrm{PhD}$ Thesis, University of Zaragoza, Spain

Martínez, E.; Angurel, L. A.; Pelegrín, J.; Xie, Y.-Y. \& Selvamanickam, V. (2010). Thermal stability analysis of YBCO-coated conductors subject to over-currents. Supercond. Sci. Tecnol., Vol. 23, No. 2, 025011, ISSN: 0953-2048

Mora, M.; Díez, J. C.; López-Gascón, C. I.; Martínez, E. \& De la Fuente, G. F. (2003). Laser textured Bi-2212 in planar geometries. IEEE Trans. Appl. Supercond., Vol. 13, No. 2, 3188-3191, ISSN: 1051-8223

Mora, M.; Gimeno, F.; Angurel, L. A. \& de la Fuente, G. F. (2004). Laser zone melted $\mathrm{Bi}_{2} \mathrm{Sr}_{2} \mathrm{CaCu}_{2} \mathrm{O}_{8+\delta}$ thick films on (100) $\mathrm{MgO}$ substrate. Supercond. Sci. Technol., Vol. 17, No. 10, 1133-1138, ISSN: 0953-2048

Rastogi, P. K. (2001). Digital Speckle-Pattern Interferometry and related techniques. Willey, ISBN: 978-0-471-49052-4, Chichester, UK 
Recuero, S.; Andrés, N.; Arroyo, M. P.; Lera, F. \& Angurel, L. A. (2005). Superconductor ceramics behaviour analyses during service by speckle metrology, Proceedings of the Society of Photo-Optical Instrumentation Engineers (SPIE), 5856, 775-785, ISBN: 0-81945856-2, Munich, June 2005, SPIE-International Society of Optical Engineering, Bellingham, USA.

Recuero, S.; Andrés, N.; Lobera, J.; Arroyo, M. P.; Angurel, L. A. \& Lera, F. (2005). Application of DSPI to detect inhomogeneous heating on superconducting ceramics. Meas. Sci. Technol., Vol. 16, No. 4, 1030-1036, ISSN: 0957-0233

Recuero, S.; Bona, M. T.; Andrés, N.; Andrés, J. M. \& Angurel, L. A. (2008). Visualization of environmental degradation in ceramic superconductors using digital speckle photography. ebur. Eur. Ceram., Vol. 28, No. 11, 2239-2246, ISSN: 0955-2219

Song, H. H.; Davidson, M. W. \& Schwartz, J. (2009). Dynamic magneto-optical imaging of transport current redistribution and normal zone propagation in $\mathrm{YBa}_{2} \mathrm{Cu}_{3} \mathrm{O}_{7-\delta}$ coated conductor. Supercond. Sci. Technol., Vol. 22, No. 6, 062001, ISSN: 0953-2048

Takeda, M.; Ina, H. \& Kobayashi, S. (1982). Fourier-transform method of fringe-pattern

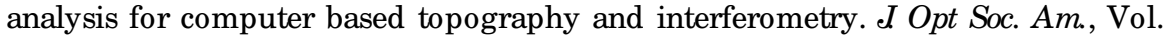
72, No. 1, 156-160, ISSN: 0030-3941

Vest, C.M. (1979). Holographic Interferometry. John Willey and Sons, ISBN: 0471906832, New York.

Wang, X.; Trociewitz, U. P. \& Schwartz, J. (2007). Near-adiabatic experiments on short $\mathrm{YBa}_{2} \mathrm{Cu}_{3} \mathrm{O}_{7-\delta}$ coated conductors. el Appl. Phys., Vol. 101, No. 5, 053904, ISSN: 00218979

Yamaguchi, I.; Kobayashi, K. \& Yaroslavsky, L. (2004). Measurement of surface roughness by speckle correlation. Opt. Eng., Vol. 43, No. 11, 2753-2761, ISSN: 0091-3286 


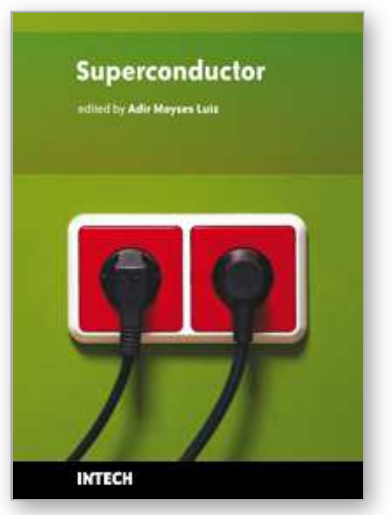

\author{
Superconductor \\ Edited by Doctor Adir Moyses Luiz
}

ISBN 978-953-307-107-7

Hard cover, 344 pages

Publisher Sciyo

Published online 18, August, 2010

Published in print edition August, 2010

This book contains a collection of works intended to study theoretical and experimental aspects of superconductivity. Here you will find interesting reports on low-Tc superconductors (materials with $\mathrm{Tc}<30 \mathrm{~K}$ ), as well as a great number of researches on high-Tc superconductors (materials with Tc> $30 \mathrm{~K}$ ). Certainly this book will be useful to encourage further experimental and theoretical researches in superconducting materials.

\title{
How to reference
}

In order to correctly reference this scholarly work, feel free to copy and paste the following:

Luis Angurel, Nieves Andres, María Pilar Arroyo, Sara Recuero, Elena Martinez, Francisco Lera, Jorge Pelegrin and Jose Manuel Andres (2010). Application of Optical Techniques in the Characterization of Thermal Stability and Environmental Degradation in High Temperature Superconductors, Superconductor, Doctor Adir Moyses Luiz (Ed.), ISBN: 978-953-307-107-7, InTech, Available from:

http://www.intechopen.com/books/superconductor/application-of-optical-techniques-in-the-characterization-ofthermal-stability-and-environmental-deg

\section{INTECH}

open science | open minds

\section{InTech Europe}

University Campus STeP Ri

Slavka Krautzeka 83/A

51000 Rijeka, Croatia

Phone: +385 (51) 770447

Fax: +385 (51) 686166

www.intechopen.com

\section{InTech China}

Unit 405, Office Block, Hotel Equatorial Shanghai

No.65, Yan An Road (West), Shanghai, 200040, China

中国上海市延安西路65号上海国际贵都大饭店办公楼405单元

Phone: +86-21-62489820

Fax: +86-21-62489821 
(C) 2010 The Author(s). Licensee IntechOpen. This chapter is distributed under the terms of the Creative Commons Attribution-NonCommercialShareAlike-3.0 License, which permits use, distribution and reproduction for non-commercial purposes, provided the original is properly cited and derivative works building on this content are distributed under the same license. 